\title{
Marc-André Kaufhold and Christian Reuter* The Self-Organization of Digital Volunteers across Social Media: The Case of the 2013 European Floods in Germany
}

DOI 10.1515/jhsem-2015-0063

\begin{abstract}
For almost 15 years, social media have been regularly used during emergencies. One of the most recent, and instructive, examples of its widespread use during a large scale scenario in Europe were the 2013 European floods. Public reporting during the event indicated, and our analysis confirms, that Twitter, Facebook (FB), Google Maps and other services were frequently used by affected citizen and volunteers to coordinate help activities among themselves. We conducted a qualitative analysis of selected emergent volunteer communities in Germany on FB and Twitter among others, and subsequently conducted interviews with FB group founders and activists. Our aim was to analyze the use of social media during this particular event, especially by digital volunteers. Our study illustrates the relevance of social media for German citizens in cases of disaster, focusing especially on the role of the moderator. Our specific emphasis was the embedding of social media in the organizing work done by said volunteers, emphasizing both the patterns of social media use and the challenges that result. We show that different social media were used in different ways: Twitter was used in the main for status updates while FB-pages were mostly intended to provide an overview. FB-groups also coordinated a multitude of activities.
\end{abstract}

Keywords: emergencies; ethnography; Europe; Germany; qualitative; social media; volunteers.

\section{Introduction}

Social media have been used in a wide variety of disaster scenarios occurring in the recent past, one prominent example being the 2013 European floods. During the flood, a large number of professional and volunteer emergency

\footnotetext{
*Corresponding author: Christian Reuter, Institute for Information Systems, University of Siegen, Kohlbettstr. 15, 57072 Siegen, Germany, e-mail: christian.reuter@uni-siegen.de Marc-André Kaufhold: Institute for Information Systems, University of Siegen, Kohlbettstr. 15, 57072 Siegen, Germany
} 
personnel as well as citizen volunteers were involved in relief activities. The latter are relevant because official authorities only have limited resources and hence volunteers may have an advantage in relation to the immediacy of information. Based on a shorter, preliminary analysis that has been published in German (Kaufhold and Reuter 2014), this article aims to uncover real and virtual self-help activities that are initiated and coordinated in the context of social media.

Widespread social media such as Facebook (FB) and Twitter in particular are now commonly used during emergencies. Founded in 2004, the social network FB is one of the most visited sites worldwide, counting some 1.36 billion active users per month. Users generally maintain a profile, a friendship network, provide text, videos or pictures inputs and can set up or join groups. Twitter, founded in 2006, is a micro-blogging service with 284 million active users per month. Public short messages (Tweets) with a maximum length of 140 characters are at the core of Twitter. Crisis mapping efforts can also be observed in tools like Google Maps (Meier 2012), a web mapping service that offers, satellite imagery, route planning and collaborative mapping functionality with annotation support, among others. These services provide appropriate structures and functions for supporting communication and coordination between stakeholders and volunteers before, during or after emergencies.

In our study, we focus on Germany, where $56 \%$ of all internet users are active on FB. Active Twitter usage is however considerably lower, counting only $6 \%$ of internet users (BITKOM 2013). Given the disparity in overall usage, the analysis of FB is of particular interest to us. Despite evidence that FB is used more extensively, a lot of research on social media in emergencies tends to concentrate on the role of Twitter, as indicated by Reuter et al. (2012). We therefore suggest that paying more attention to other media such as FB or Google Maps may add value to the research discourse. We contribute to this issue with a case study that examines the use of FB, Google Maps, Twitter and additional media during the 2013 European floods.

Our research questions are as follows: How were different types of social media used during the European floods? How was social media used to organize volunteers? And: What are the challenges for collaboration support?

\section{Related Work}

The use of social media in emergencies has been extensively researched. For nearly 15 years, the public has used social media in crisis situations (Reuter et al. 
2012): after the terrorist attacks of September 11th 2001 for example, wikis created by citizens were used to collect information on missing people (Palen and Liu 2007), while photo repository sites were used by citizens to exchange information following the 2004 Indian Ocean tsunami (Liu et al. 2008).

\subsection{Cases of Social Media Use}

Many published research papers, as we have suggested, have mainly focused on the use of Twitter during various disasters in the USA since 2008. This in turn leads to the observation of differences between the use of Twitter in crisis situations as compared to general use (Hughes and Palen 2009). Observing the Tennessee River technological failure in 2008 outlined the phenomenon of broadcasting emergency information (Sutton 2010) while the Red River Floods in 2009 highlighted the broadcasting by people on the ground as well as activities of directing, relaying, synthesizing, and redistributing (Vieweg et al. 2010). Studies on the Oklahoma Fires of 2009 highlight the role of retweeting (Starbird and Palen 2010), and the attack on four police officers in Lakewood, Washington in 2009 also demonstrates Twitter's ability to organize and disseminate crisis-related information (Heverin and Zach 2010).

Other studies have provided a more international backdrop. The analysis of the 2008 Sichuan earthquake demonstrated that people gather and synthesize information ( $Q u$ et al. 2009). For instance, the case of the 2010 Yushu earthquake in China shows that microblogging is used to seek information about other people's statuses (Qu et al. 2011). Moreover, a study of the 2011 Egyptian uprising shows how the crowd expresses solidarity and does the work of information processing through recommendation and filtering (Starbird and Palen 2012). The mass panic at the Love Parade music festival in Germany in 2010 as well as the 2010 outbreak of the volcano Eyjafjallajökull in Iceland outlined the need for two-way communication (Reuter et al. 2012). This also came apparent in a study of the attacks, which took place in Norway in 2010, where the notion of peripheral response has been developed in relation to emergent forms of agile and dialogic emergency response (Perng et al. 2012).

Reuter et al. (2016) summarize the state of the art on emergency services' perception of social media. Their survey with 761 emergency service staff across Europe points out that the majority of emergency services have positive attitudes towards social media and that it is more used to share information (44\%) than to receive messages (19\%) (Reuter et al. 2016). A survey with 241 US emergency managers at the county level shows that only about half of these agencies use social media. Although authorities already experiment with the 
use of different tools, there is a lack of a clear understanding of what tool to use, as detected in interviews in different European countries (Reuter et al. 2015a).

Further research investigates the interrelation between the activities of the authorities, those of professional response teams and of volunteers. A study on the 2011 Vancouver Riots revealed "unintended do-it-yourself-justice" whereby citizens overruled authorities and enforced justice on their own terms and by their own means through social media (Rizza et al. 2014). Another study examined the work of Public Information Officers and argues that members of the public "have a changed relationship to the institution of emergency response" through their use of social media (Hughes and Palen 2012). In relation to use by formal institutions, a study on 2012 hurricane Sandy reveals that very few departments used online channels in their response efforts and that communication differed between fire and police departments and across media type (Hughes et al. 2014). Moreover, it has been shown that citizens can handle those activities that are unlikely to be done by official emergency services, e.g. recovering lost pets (White et al. 2014). Another study suggests that volunteer groups in emergencies will in the future be challenged to mature and improve according to these enhanced possibilities, so that "professional responders will begin to rely on data and products produced by digital volunteers" (Hughes and Tapia 2015).

Research regarding types of users active on social media began by identifying individual roles and proceeded with the development of role typologies. Hughes and Palen (2009) initially identified information brokers who collect information from different sources to help affected citizens. For Starbird and Palen (2011), the second step was to recognize the actions of remote operators as digital volunteers who progress from simple internet-based activities like retweeting or translating tweets to more complex ones, e.g. verifying or routing information. To further differentiate potential user roles, Reuter et al. (2013) distinguish between activities in the "real" world as opposed to the "virtual" world: real emergent groups (Stallings and Quarantelli 1985), whose involvement usually takes the form of neighborly help and work on-site, and virtual digital volunteers (Starbird and Palen 2011), who originate from the internet and work mainly online. Ludwig et al. (2015b) build on it and address these groups by enabling the detection of physical and digital activities and the assignment of specific tasks to citizens. Based on a timeline and qualitative analysis of information and help activities during the 2011 Super Outbreak, Reuter et al. (2013) suggest a more specific classification of Twitter users in different roles: helper, reporter, retweeter, repeater and reader. Kaufhold and Reuter (2014) additionally suggested the role of the moderator. 


\subsection{Studies of the 2013 European Floods}

There is a body of work available which uses data from the 2013 European floods. Mildner (2013), for instance, describes his experience of setting up the flood map of the German city of Dresden. Conducting semi-structured qualitative interviews with members of the administrative staff in the German city of Passau, Wittmann et al. (2015) show that a hybrid governance structure was employed throughout the flooding. Fuchs et al. (2013) confirm the potential of Twitter as a distributed "social sensor" but at the same time highlight some caveats in interpreting immediate results. Kaufhold and Reuter (2014) highlight the excellence of Twitter as a platform for status updates whilst at the same time showing that a variety of virtual and real relief activities was coordinated, mainly in FB-groups. Analyzing Twitter during the European floods, Reuter and Schröter (2015) revealed pragmatic (linguistic) barriers resulting from irony, wordplay, and ambiguity, as well as in retweet-behavior. They argue that existing software has to be adapted and improved for German language characteristics. All these papers identified several challenges and areas for improvement.

Some papers have tried to address these challenges: Reuter et al. (2015b) designed, implemented and evaluated “XHELP," a cross-platform social media application. They conclude that "a cross-platform search, especially with time and location filtering options, contributes to the channeling of the information flow." Backfried et al. (2015), "aim to take the cross-media approach one step further" by not only including data from multiple social media platforms, but also by combining it with information from traditional media. They "describe some of the links and linking behavior encountered during the floods [...] from the perspective of Twitter and FB." Besides these approaches, which specifically arose from the European floods, Sackmann et al. (2014) present "Hands2Help," an app-based coordination system intended to support incident commanders and control centers in volunteer coordination.

\subsection{Research Gap, or: State of Play}

To summarize the state of the art, most studies have focused on the use of Twitter, perhaps due to its frequency of use in the US (Reuter et al. 2012). However, in many European countries such as Germany - where our study pertaining to the European floods was conducted $-56 \%$ of all internet users actively use $\mathrm{FB}$, whereas the active usage of Twitter is significantly lower at just 6\% (BITKOM 2013).

One recent case of social media use in emergencies in Europe are the European floods. Some studies already engaged with this event. However, either they 
are design-oriented (Sackmann et al. 2014; Backfried et al. 2015; Reuter et al. 2015b); do not cover the overall event by examining only one particular city (Mildner 2013; Wittmann et al. 2015); or considered “only” Twitter (Fuchs et al. 2013; Reuter and Schröter 2015).

Our study aims, then, to cover various media "beyond Twitter" in Europe and study the European floods in three locations across Germany using both social media and interview data.

\section{Case Study: 2013 European Floods}

The European floods (Figure 1) in June 2013 were an event in which volunteer activity played a major role. Thirty-five federal states in seven European countries had to declare a state of disaster in multiple districts, including 55 districts in Germany including the Federal States of Bavaria, Lower Saxony and Saxony-Anhalt. This disaster caused the deaths of eight people in Germany and cost the states an estimated 6.7 billion Euros. The German armed forces (19,000 soldiers) and fire services (75,000 firefighters) participated in the relief efforts, along with the German Red Cross and other relief organizations who provided medical and other care. Besides the large number of professional forces and voluntary organizations who were involved, many volunteers and affected people participated by building up flood barriers, filling and piling up sandbags, donating work material and goods for victims, distributing food and providing emergency shelters.

The use of social media in this case has been acknowledged and even utilized by the traditional media. Volunteer activities were planned and coordinated, emotional support was given and eyewitness reports were shared using these media. Aside from Twitter, FB was the most-used application. One hundred and fifty seven pages and groups relating to the keyword "Hochwasser" (English: flood) were created and more than 600,000 people were members of such groups or liked the pages. For $47 \%$ of these communities the focus was on local geographical locations such as counties or towns or districts. Thirty-four percentage dealt with forwarding and exchanging information and $27 \%$ considered them to be relief platforms (Karsten 2013).

In the following sections we describe three cases and six related FB-communities that we examined within our study. We chose three different areas to establish a modest degree of generalizability across federal borders. We selected FB-pages that indicated above-average activity and reach (in terms of FB-likes) to act as a broadcasting medium (Sutton 2010), and FB-groups representing local (self-help) communities that also showed a brisk degree of activity and 


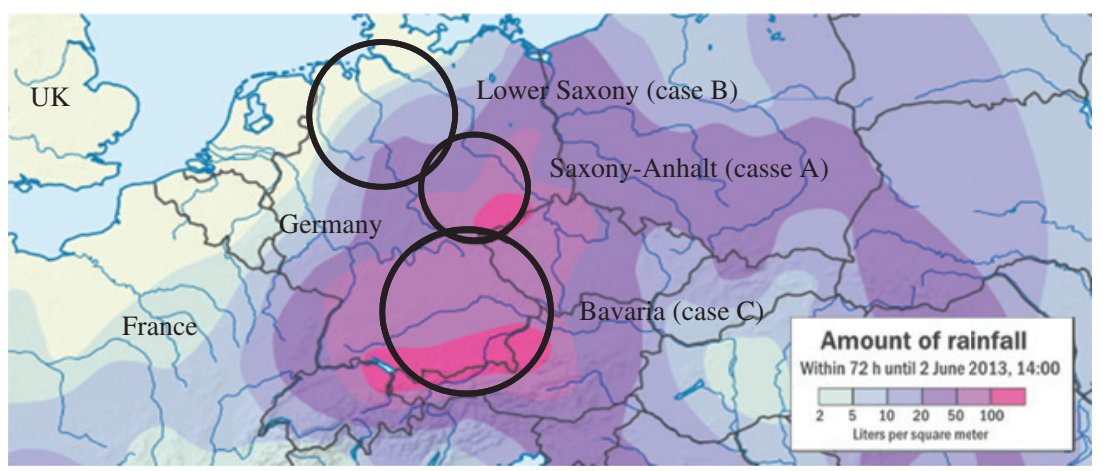

Figure 1: Amount of Rainfall and Cases during the Floods.

more specifically dealt with the mediation of help supply and demand (Reuter et al. 2013).

\subsection{Case A: Saxony-Anhalt}

In Saxony-Anhalt, the floods had a significant impact on the town of Magdeburg where about 23,000 people had to be evacuated east of the Elbe River. Also, a transformer station was threatened, meaning that a potential ingress of water would have endangered the electricity supply of 30,000 households for several months. The team of the FB-page, "Flood News Magdeburg," for instance, aimed to browse through, evaluate, select, and share relevant information about the developing situation. Additionally, the FB-group "Flood Magdeburg - Requests for help" tried to provide a holistic situational overview with links to further groups or pages and information on hotlines and "donation camps."

\subsection{Case B: Lower Saxony}

The case of Lower Saxony shows communities seeking to support help activities distributed throughout the whole federal state. The description on the FB-page "Flood Lower Saxony" defines its goal as collecting and exchanging information about the flood, e.g. water levels, photos documenting the damage, evacuations and situational trends regarding Lower Saxony. The FB-group "Flood Lower Saxony - Offer/Search" coordinated the communication between people affected and those offering assistance, and presented conventions of use in the group description and as a fixed post. 


\subsection{Case C: Bavaria}

In Passau (Bavaria), the water supply was temporarily contaminated by some of the heaviest floods ever to affect the Danube River. Teaching at schools in the vicinity and the local were disrupted, while in the nearby town of Deggendorf more than 6000 citizens had to be evacuated when the dam failure burst, resulting in the flooding of low-lying areas. The team of the FB-page "Passau cleans up” established a local and structured organization consisting of headquarters, coordinator and scout units to support the overall coordination of relief activities in Passau. The FB-group "Moms help” originating with a group of (pregnant) women, supported relief activities and took an active role in the response and advanced recovery phase.

\subsection{Methodology}

Our empirical study, which has partly been reported in German (Kaufhold and Reuter 2014), aims to examine the use of social media for the coordination of volunteer relief activities. For this, we initially analyzed six FB-communities, evaluated tweets and conducted seven semi-structured interviews (Table 1). We also make occasional use of further sources. Our work is, then, based on the case

Table 1: The Three Cases of our Empirical Study.

\begin{tabular}{llll}
\hline Case & A & B & C \\
\hline $\begin{array}{l}\text { State } \\
\text { FB-Pages }\end{array}$ & $\begin{array}{l}\text { Saxony-Anhalt } \\
\text { Hochwassernews } \\
\text { Magdeburg (Flood News } \\
\text { Magdeburg) }\end{array}$ & $\begin{array}{l}\text { Lower Saxony } \\
\text { Hochwasser Niedersachsen (Flood }\end{array}$ & $\begin{array}{l}\text { Lower Saxony) } \\
\text { Passau räumt auf } \\
\text { (Passau cleans up) }\end{array}$ \\
FB-Groups & $\begin{array}{l}\text { Hochwasser Magdeburg } \\
\text { - HilfsGESUCHE (Flood }\end{array}$ & $\begin{array}{l}\text { Hochwasser Niedersachsen - } \\
\text { BIETE/SUCHEa (Flood Lower Saxony }\end{array}$ & $\begin{array}{l}\text { Mamas helfen } \\
\text { (Moms help) }\end{array}$ \\
& $\begin{array}{l}\text { Magdeburg - Requests } \\
\text { for help) }\end{array}$ & - Offer/Search) & \\
Twitter & $\begin{array}{l}\text { Search term: flood } \\
\text { (“hochwasser”) }\end{array}$ & & \\
Interviews & A (moderator) & B (moderator) & C (moderator) \\
& $\begin{array}{l}\text { D (helper; employed at } \\
\text { police) }\end{array}$ & $\begin{array}{l}\text { E (helper; employed at water } \\
\text { management) }\end{array}$ & F (moderator) \\
& & G (helper; employed at fire service) & \\
\hline
\end{tabular}

aThe group was renamed to "Hochwasser - die Helfer-Gruppe (Flood - the Helper-Group)" on July 20, 2015. 
study approach described by e.g. Stake (1995) and Yin (2014) and which allows for the detailed exploration of a phenomenon within some bounded context (see also Creswell 2013). Yin, in particular, allows for comparative work across multiple cases and distinguishes exploratory and explanatory case studies. Our work on the 2013 floods clearly explores data across what we can reasonably describe as a bounded context (the floods), but which nevertheless compares across three individual cases.

The FB analysis explored messages in three groups and from three pages from three federal states in order to analyze processes regarding interaction, structuring, and task sharing. Starting on June 6th, FB-group and page activities were downloaded and updated regularly as complete HTML documents to extend and refine our analysis. The last update was performed on October 31st. Additionally, news articles in the context of the floods were archived as PDFs and more than 50 screenshots were saved in order to document the use of Google Maps in the affected areas.

In addition, from June 6th to June 27th 2013 nearly 80,000 tweets containing the term or hashtag "hochwasser" (English: flood) were archived using the tool “Tweet Archivist Desktop.” We used the term “hochwasser” because it was listed among the top trends in Twitter and was mentioned in several media. Our Twitter analysis consisted of two steps: First, we explored the whole dataset to extract quantitative features (e.g. overall number and temporal distribution of tweets, retweets, media, embedded URLs; tweets and retweets per user; other hashtags used along with "hochwasser") and conceive the structure and topics of the information space. Subsequently we focused on a reduced dataset of 1602 tweets (containing relevant keywords like "urgent," "need," "offer" or "help") to examine how and in what ways relief activities were shaped in and by Twitter.

In the next step of our empirical study, we recruited moderators and helpers of the FB-communities in question via e-mail and private FB-messages, conducting both local and phone interviews to gain insights into their work practices, ways of mobilizing resources (Perng et al. 2012) and self-organization processes (Starbird and Palen 2011) as well as identifying the potential ways to support them. The interviews were designed to specifically address our interests. Initially, the interviewees were asked whether they belonged to an organization of civil protection or had competencies regarding professional crisis response. Following this, we focused on the tasks and activities of the respondents, whereby we were particularly interested in the relationship between online or virtual activity and mobilization "on the ground." The third part concentrated on task-sharing processes, during which potential cooperation with emergency services was discussed. Finally, the interviews posed questions at an ICT level by evaluating FB functions and discussing technical support potential. Interviews were audiorecorded and transcribed for further analysis. 
In our subsequent analysis we employed "open” coding (Strauss and Corbin 1998) i.e. gathering data into approximate categories to reflect the issues raised by respondents based on repeated readings of the data and its organization into "similar" statements. These categories reflect the structure of the following results section. While the analysis was conducted in German, the quotes selected for this article were translated to English by the authors.

\section{Results I: The Use of different Types of Social Media and ICT during the Floods}

Focusing mainly on the use of FB and Twitter during the floods, the following sections present the analysis of the use and reception of specific functions of FBgroups and pages, as well as the integration of social media with other ICT.

\subsection{Use Differences Among Different Services}

Although Twitter was used extensively in flood situations, especially for distributing information and situational updates, our results show that it generally tended to take the form of a broadcast medium for shaping cross-platform structures and extending coverage (Reuter et al. 2015b): The coordination of relief activities was rarely observed in the Twitter sphere alone, but took place within a complex ecology of both online and offline facilities. This could, to some extent, be a corollary of low Twitter penetration in Germany, but it is consistent with Hughes et al. (2014) who showed differences in use across media platforms. Accordingly Twitter seems to be used for real-time notification, and FB for community engagement (St. Denis et al. 2014). In our case, local and subject-specific groups emerged on FB, who cooperated extensively with other groups/pages. In addition, the interviewees mentioned their awareness of certain functionalities in social networking which induced them to stick to platforms they were familiar with (in this case FB) during the floods (A, 17:18; B, 50:36; C, 40:26).

\subsection{Facebook Group and Page Functionalities}

\subsubsection{Group Discussion and Group Description}

On entering a group or page in $\mathrm{FB}$, the group discussion or the page chronicle (see Section 4.2.3) are the most prominently visible features. While the chronicle lists 
items sorted exclusively by the date of their creation, in a group discussion, the date of the item comments also influence the position of the item. Exceptions are "fixed postings" which are always at the top of the list and which were used in all cases either to (a) introduce the purpose of the group, (b) present the group's conventions and use of its functions, (c) give a general overview of the emergency and existing infrastructure, or (d) prioritize important or recent information. In the cases A and B, the fixed posting more or less consisted of the group description, including policy statements, probably because the fixed posting is more accessible and central on the user's screen. To reflect the group's purpose, statements like these were disseminated:

- "Help offers are collected here, so that voluntarily helpers have a contact point" (Flood Magdeburg - Requests for help, case A).

- "Although we are no longer under water, there are still plenty of help requests, so we needed to find something new [...]. We need YOU as a family mentor" (Moms help, Case C).

- $\quad$ "If ever there is another disaster in future, we would like to offer this platform to mediate help” (Flood Lower Saxony - Offer/Search, case B).

While in case A the statement reflects the general purpose of the group, case $\mathrm{C}$ indicates that the focus of activity was shifted during the course of emergency and case B even strives to be a platform for future disasters. In terms of conventions, case A attempts to lay out a protocol, suggesting that a posting such as a help request should contain at least an address and the goods or services (lifts, sleeping-places, etc.) needed, and that users should only publish help requests in a clearly stated fashion. In case B, interested people are told that help requests are organized on the discussion wall and files have been created with information on provisions, shelters, furniture or materials to enable subject-specific communication via comments (see Section 4.2.2). Contrary to case A, they explicitly ask posters not to "post addresses, phone numbers or contact points without consultation." Two distinct approaches to issues of privacy could clearly be distinguished and are examined below. Both groups mention that they will delete inappropriate postings (case A) or when they have been successfully processed (case B). Furthermore, the mediation process of family mentoring is described in detail in case $C$.

"Flood Magdeburg - Requests for help" in particular tried to give an overview of the emergency by providing (a) a list of other FB-groups and pages that have a more global (e.g. Saxony-Anhalt), regional (e.g. Magdeburg, Elbe-Havel) or topical (e.g. help offers, emergency shelters) focus and (b) a list of official donation hotlines and donation camps. 


\subsubsection{Group Files and Documents}

Group files (resp. documents) were used as descriptive sources and to enable topicrelated communication (Figure 2). Interviewee B quotes her previous knowledge and the availability of group functions (files, documents and photos) as crucial factors in the use of FB during the floods, to structure efforts:

"If you create a group you can get people, who you promote to admin, so that you can divide labor. Then I can create folders in a group to sort certain things like help offers and requests in this case, which we managed with files, or that you can use photo albums to classify certain categories. You could structure this, which was crucial for me" (B, 50:26).

While in most cases the administrators managed the document's title and content, other members used the comment section of the document for communication. For instance, "Moms help" started to mediate "family mentors" in mid-October with the help of FB-documents, whereby one document enabled potential family mentors to show their willingness and the second provided a sorted list of those already registered, ordered by postcode. Other files consisted of lists of one's own or foreign group administrators, blocked users, group supporters or general information. In another document, members were instructed to publish their help offers, and the document itself gave an example of how to structure these. Also, the files were tagged by the abbreviations "done for now" and "current" or by an exclamation mark to express the status or the urgency (Figure 2, right). Using the file function to organize help offers was described as a critical task:

"We originally tried to do this by using files but within three days we had reached our limitations. Answers were inserted into files as comment, but once there are 200 comments; nobody reads 250 comments to find out: 'Ah, the gumboots were up there”' (C, 50:12).
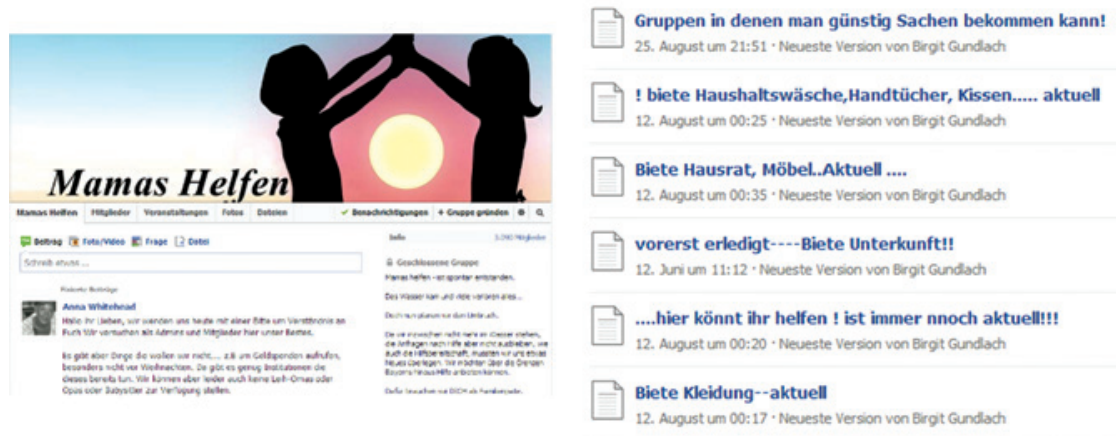

Figure 2: “Moms Help” Group Discussion and List of Files. 


\subsubsection{Page Chronicle and Page Info Section}

In contrast, the page chronicle is generally managed by the page team members, so that regular users can only comment on page postings and a specific comment section, kept apart from the chronicle itself. Page teams often used the page info section to clarify their objectives. The team of "Flood News Magdeburg" regularly published status updates regarding the severity of the situation, volunteer and material requirements and general information about recommended equipment as well as posts with empathetic intent, such as thanking volunteers for their efforts. They describe their task to browse through existing information, to evaluate it, to select information considered to be relevant, and to share it on its page. It can thus be thought of as generating collective intelligence (Hollan et al. 2000). In addition, the activities of structuring and synthesizing information can be observed on the wall summarizing information on several areas affected by the floods:

Discussions often emerged in the comment section of these messages, where potential helpers initially expressed their need for information and elements of a verification process became visible: There was a higher probability that information would be assumed to be correct if it was confirmed by the page moderator (Table 2, left). In contrast, the statements made by other users were sometimes questioned with greater intensity, indicating a certain degree of self-regulation through the crowd's mistrust of unconfirmed information (Table 2, right).

The photo function was also utilized by several groups and pages (Figure 3). For instance, in "Flood Lower Saxony - Offer/Search" various photos are to be seen which document damage and other effects of the crisis, and the (process of) help activities such as "piling sand bags" or relief and evacuation efforts. Comments on flood-related photos on the one hand usually contained emotional messages expressing solidarity, sympathy and identification with the helpers. Interviewee $\mathrm{F}$ states that they published photos intentionally:

\footnotetext{
"We always uploaded pictures of people [...] and I think this was very good for the emotional processing (of the floods) that this mutual photo exchange took place here. And in a way it was good for motivation too, of course." (F, 24:00).
} 
Table 2: Two Examples of Information Verification.

[02:00] Eric: Where exactly in Pechau and Zollhaus??

[02:00] Basti: I am driving to Zollstrasse. Where do I have to register???

[02:02] Thomas: It will be explained at the sports field in Pechau. Leave the car there [02:02] Flood News Magdeburg: In Pechau, register at the sports field! At Zollstraße, you will see it directly on arrival

[02:03] Mirko: In Penchau you will be met at the sports field and at Zollstraße everything is lit up
[02:36] Janine: In Westerhuesen I think they are also looking (for helpers)!!!! [02:40] Christian: \#Janine Krause sure? Where exactly?

[03:18] Markus: New contact point. Virchowstraße [03:20] Jana: How certain?

[03:20] Simon: Is that certain, Markus???? [03:40] Markus: Certain, but they are still constructing on-site. It makes little sense to come here yet
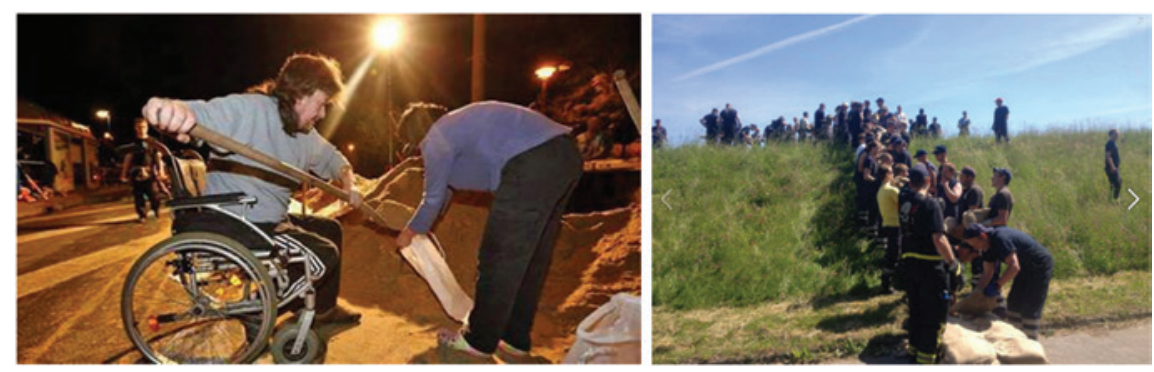

Figure 3: Photos with Emotional and Cohesive Appeal (Sources: "Flood Lower Saxony - Offer/ Search"; "Flood Lower Saxony").

On the other hand, coordination efforts occasionally took place and new help offers were disseminated in the comment section, indicating that the emotional appeal of photos can also serve the purpose of mobilizing additional helpers and resources (White et al. 2014).

\subsubsection{Problems with Private Messages: “Oh I didn’t see it”}

Besides page and group functions, private messages were also used in certain situations. To filter and verify information as well as support a clear overview, interviewee B adjusted group policy in such a way that comments were not published on the wall until an administrator had confirmed them. Interviewees used private messages to contact helpers and affected people:

"At busy times, especially in the initial phase [...], suddenly there were 17 private messages from people who wanted something from the group. Then I could simply open a new tab for each person and work through it and also re-sort the information in files” (B, 50:26). 
However, this procedure has the disadvantage that messages to contacts, who are not part of one's friend list, are put into the folder "other" and the user is not notified:

“Many people aren't aware of the folder 'other' and FB gives no notification of other messages. And 2-3 weeks later the answer came back: 'Oh I didn't see it.' For emergency situations, it would be great if you could answer more directly” (A, 33:10).

\subsection{Twitter - Retweets and Situational Updates}

Representing 17.93\% of the entire Twitter dataset, the account @_BB_RADIO_H2O has regularly and automatically published information on water levels based on data provided by the Federal Waterways Administration. As these tweets contain situational updates and geo-referenced information, they contribute to overall situational awareness. Tweets generated by other accounts comprise links to webcams, which give the users an idea of how the situation on the ground looks. With 13.86\%, the account @Hochwasser2013 mainly published retweets. Under the accounts @FeuerwehrRT and @THW the fire service and the THW (federal agency for technical relief) retweeted tweets automatically, including the hashtags \#hochwasser and \#feuerwehr (fire department) resp. \#thw. A great number of captured accounts were limited to or mainly disseminated retweets, which constitute $46.45 \%$ of the dataset. The news channel "MDR Sachsen-Anhalt" showed a high level of activity with 1071 tweets (1.34\%) on the account @MDR_SAN. On June 3rd, 4:03 AM, MDR offered to retweet important messages: “@MDRaktuell: \#Flood: Where are \#Volunteers needed? Please tweet, we retweet.” Alongside MDR, many other accounts based on traditional media, especially TV and radio stations, print media and their associated websites also produced some of the highest numbers of tweets.

To further analyze tweets related to civic relief activities, we reduced the data set by excluding official accounts dealing with politics, media and companies. When reflecting the remaining data, it became apparent that help activities in particular can be identified by recurring expressions such as "urgent," "needed," "offer," or "help." Filtering the data set according to these expressions alone resulted in a set of 1.602 tweets. Overall, only a small amount actually dealt with relief activities. The majority belonged to situational updates (e.g. water levels). Among the communities examined, only "Flood Lower Saxony" used the account @hochwasserniede to distribute information on Twitter, but each tweet contained a URL referencing their activities on FB. Furthermore, none of the interviewees had a personal Twitter account or considered creating one during the floods. 


\subsection{ICT used alongside Facebook and Twitter}

\subsubsection{Geo Mapping with Google Maps}

Social media relief activities were supplemented by a vast range of external tools. The team of the FB-page, "Flood News Magdeburg," for instance, created a Google map (similar work was done in other cities). Flooded areas, shelters, sand bag filling stations, threatened dikes, a need for relief forces or transport facilities were illustrated with the help of various markers, polygons and attached information windows (Figure 4). In addition, the description of the map was used to introduce its purpose or additional resources. In the comment section, numerous comments were made by helpers who appreciated such maps and wanted to support the up-to-datedness of the map with situational updates (Table 3, left).

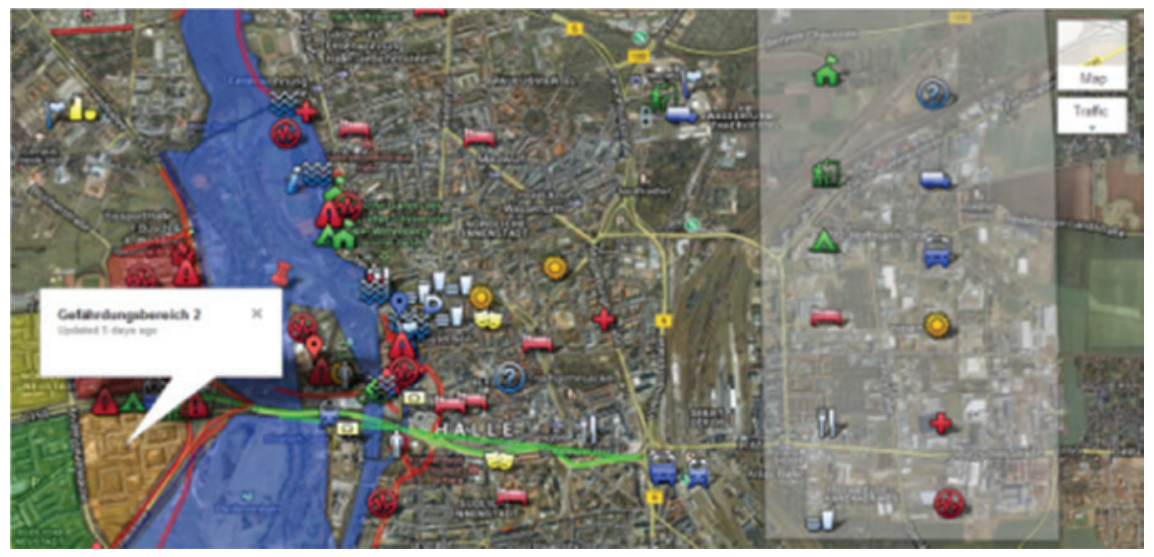

Figure 4: Google Maps in the City of Halle.

Table 3: Positive Reception and Obstacles of Google Maps.

Marko: The map is really brilliant. Keep it up-to-date, we will gladly continue to work with it

Eriu: Really helpful application for the coordination of flood relief activities Anon: Many thanks for this great map. Using it yesterday, I found a suitable place of action and after work was done there, I found the next place
Jschlademann: GREAT MAP!!! THANKS! Please update: The physiotherapy practice on ErnstKönig-Strasse does not require help anymore. The annotation can be deleted. MANY THANKS!! Philipp: Why is not the street at the surface mine listed as blocked at the map? It has been completely flooded for several days now Joshwa: Please update, some entries are older than $8 \mathrm{~h}$ and make the map unclear and useless for potential helpers:/ 
These comments reveal the potential of crisis maps to visualize geo-referenced information, but clearly show the challenges that lie in ensuring information is both clear and up-to-date (Table 3, right).

Furthermore, interviewee B indicated problems adapting to Google Maps as she tried to "create a map where volunteers sign in [...], but did not understand how to set a marker” (B, 56:59).

\subsubsection{Organized Support: Live Blog and Google Docs}

"MDR," the public broadcasting company in some federal states, organized a moderated live-blog: besides selected tweets and FB-posts, manual posts by users (and their own recommendations e.g. accounts for donations or seek/offer-platforms) were made available (Figure 5, left). Furthermore, MDR used Google docs to share a public spreadsheet regarding flood-related information and guidance. In order to obtain and list volunteers' addresses and phone numbers, the team around interviewee F created a Google form: "And then we created a Google form and distributed it via campus blog and student council Facebook pages. We got more than 1000 entries overnight [...]” (F, 01:53).

\subsubsection{Custom Web Tools}

Custom web tools were developed in addition to the above to structure the process of capturing and matching help requests and offers. In the area around Dresden, tweets were automatically generated by the account @FluD-
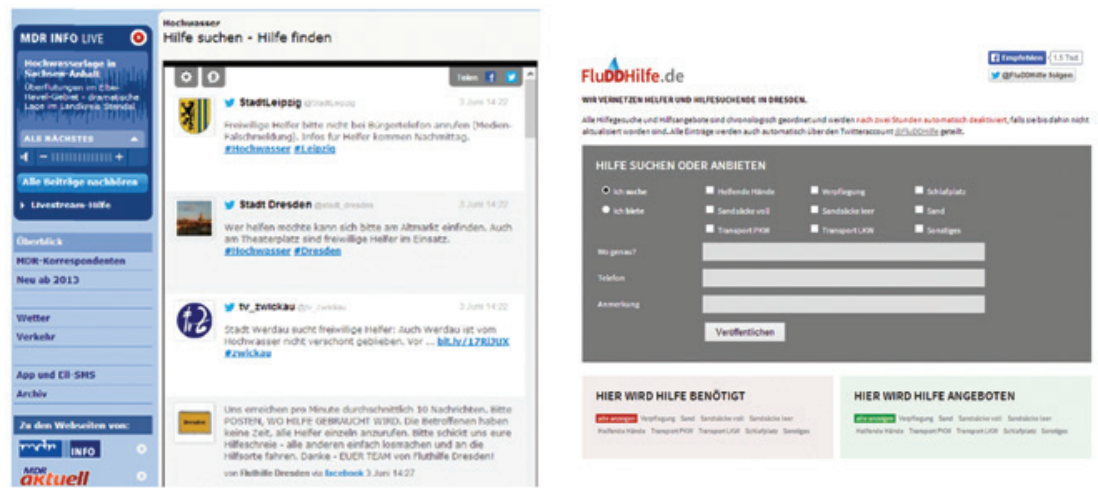

Figure 5: MDR Live Blog and FluDDHilfe Website. 
DHilfe whenever a user had created a help request or offer on the fluddhilfe. de website (Figure 5, right). By cross-referencing in this way, the developer established a bidirectional connection between both platforms. Interviewee $\mathrm{F}$ also mentions the use of the flut.stomt.de website, a similar tool to collect help requests and offers in different regions, highlighting coordinative features: "And it was really nice that you could enter how many helpers were required and click "I will go there" and then the tool's counter (of required helpers) went down" (F, 35:43).

In addition to these publicly accessible artifacts, interviewee $\mathrm{C}$ used a local Excel spreadsheet to organize demands from people and collection points, while interviewee B, along with other administrators, used Dropbox to make certain information and documents available to a limited audience of users.

\section{Results II: (Self-)Organization with Social Media}

Social media was used to advance communication, to supplement existing channels and to support overall organizational efforts to overcome the floods. Data concerning information processing activities and the qualitative characteristics of social media information in this context will be presented in the following sections.

\subsection{Organization and Task Sharing in Volunteer Communities}

In all the cases we examined, there were elements of task sharing within the internal team of moderators. The team of the Lower Saxony case split tasks as follows:

"She went to Schönhausen and Breitenhagen and gained her own impressions. At the time I was still reacting at a distance. She then called me [...]: 'This and that is needed. Could you please check if anybody has that?” (B, 15:52).

Interviewee B followed up by checking existing FB-documents or asking for offers. In terms of other virtual communities, a private coordination process was established in a way that addresses and persons were treated confidentially for the purpose of data privacy: "That means there is a private group of moderators where there are some admins who made a reliable impression" (B, 43:50). Interviewee $\mathrm{E}$ also states that many resources were organized privately (E, 06:17) and that too few affected citizens articulated their demands over FB for efficient pro- 
vision, possibly due to lack of internet or relevant facilities and/or skills within the disaster situation (E, 27:40). According to interviewee $\mathrm{G}$, trucks of resources were transferred to the disaster zone, where the respective resources were not needed at all:

"After the floods, the few deployments from the various help organizations that I saw were catastrophic. When people returned to the locality for two or three days, I cannot pull up with countless trucks containing furniture, if no houses have been cleared out yet" (G, 06:07).

Interviewee E reported a similar incident of someone "sending 120 beds to Breitenhagen," although the "people of Breitenhagen did not want any old hotel beds" (E, 35:56). Besides the inefficient allocation of resources, problems with transportation allocation arose because the coordinators were subject to a degree of information overload (far too many messages) (E, 34:06).

In Passau, interviewee $\mathrm{C}$ describes a cross-platform division of work where volunteers provided collection points, published them in newspapers and later on were supplied with material donations. Afterwards the moderator team arranged distribution and transport to the affected population. Within FB, and in contrast to the Lower Saxony case, a public coordination process was established in Passau: "We cooperated with Flood Help Bavaria, Passau [...] and all the others who really were active there. We posted the help offers and requests everywhere" (C, 20:00). Nevertheless, the cross-platform dissemination of posts had the drawback of potential information inconsistencies, because status updates were not always announced on every platform:

"The problem was that we had eight help requests in eight groups [...]. There were conversations like 'I already got help, everything is done' - 'Really? The request is still open over here' - 'Oh sorry, I forgot to update it'. The response between the groups or help activities did not work" (C, 55:56).

In addition to that, the relief efforts in Passau were supplemented by the student initiative, "Passau cleans up." After using Google forms to collect volunteers' addresses and phone numbers, a coordination network was built up:

"At the beginning we set up a mailing list. We built up a local coordination network, meaning we had [...] two headquarters. Then there were (seven) coordination points with coordinators, whereby each coordinator had 3-5 scouts who walked through the streets along with fire service and THW personnel, coordinating how many volunteers and what kind of equipment was needed. This was communicated back to the coordinators, who then forwarded the information to the headquarters. From the headquarters, we sent the volunteers and their equipment to the relevant location" (F, 04:28). 
In order to reach a broader audience (further to their campus blog), i.e. for sharing the Google forms, clarifying conflicting or inaccurate information and reducing fearmongering, the students created a FB-page for the communication of information (F, 05:11). The page was also used to gather help offers and requests via private messages and public page posts (F, 10:11).

\subsection{Roles of Digital Volunteers: The Moderator}

Several social media roles (see Section 2.1) could be observed in our case studies which were connected both to the core activity of helping as well as to the gathering, amplification and moderation of information. The interviews clearly focused on the role of moderators, but also provided us with insight on their cooperation with other types of users.

In the beginning, the role of the moderators, represented by interviewees $\mathrm{A}$, B, C, and F, often initially encompassed simple activities but saw their efforts evolve into the more enhanced role of founding and organizing communities of affected citizens and volunteers. Interviewee $\mathrm{C}$ started her voluntary work by collecting information about activities in the neighborhood, but also went on to organize not only appeals for donations but also to manage collection points (C, 04:48). Likewise, interviewee B describes in detail how she mediated messages containing offers by volunteers to people affected by the floods and how she organized transports:

"Messages about hygiene articles and disinfectants were managed privately in the background. People just said. 'I have such-and-such. Where should I send the packet?' And then I sent them a PDF with the address” (B, 09:49).

Interviewee A started her activities on "Flood News Magdeburg” by identifying demands for help and mediating volunteers, which led to the foundation of "Flood Magdeburg - Requests for help":

“There were plenty of requests: 'Where can I help?' If you registered there and visited the page 10 min later, you wouldn't be able to find your own posting anymore. New postings were published every few seconds and you couldn't find anything” (A, 03:45).

She thus describes her task as "providing a clear view of (relevant) information and sorting out (spam)" (A, 29:09). However, her aim was also to reduce timeconsuming exposure for others by "clicking all the pages and getting the messages" (A, 28:37) and further by "updating information, answering requests and maintaining contact with on-site volunteers to get current information” (A, 05:20). 
Furthermore, according to interviewee F, the team of "Passau cleans up" exploited the style of message writing to create acceptance both for citizens and moderators, respectively:

"We paid great attention to our style of writing. We tried to formulate it in a way that made it clear help was mutual and not condescending. And of course you've got to try to express yourself in a way that is not too complex because there are people out there who kept on saying 'Well it's not just students you know but the town population, too' because it was only students who were mentioned in the press. So you see we were a bit afraid that if we conveyed things in a complex way, we would lose volunteers; that they would pack it in because they thought we were arrogant" (F, 28:39).

Summarizing the moderators' core activities, they entailed the mediation of volunteer activity and matched citizens' demands with offers of help by utilizing and integrating social media functions and ICT which contributed to the process of structuring the rich information supply.

A prominent role is the helper who performs real, virtual or even combined activities to support affected people. On-site helpers often commented on page postings to supplement or update published information, and used information offered by postings or Google maps to find new places requiring help or to ascertain which (material) resources were sought. Interviewee E, for instance, was involved in the filling of sandbags, cleanup activities (E, 03:32) and the collection of donations for affected citizens (E, 14:14). She also provided psychological assistance from home, something she was not prepared for initially (E, 2:49).

Our research also identified the role of the amplifier, or retweeter in the context of Twitter. The automatic retweet services and the manual retweet offers described in Section 4.3 contribute to the amplification of specific information. Although FB does not provide direct functionality such as retweets, some FB-page teams described their task as to identify, evaluate, select and publish and therefore amplify - relevant information. A common activity of "Flood News Magdeburg" was to disseminate structured and synthesized postings to provide a situational. Additionally, FB provides mechanisms for adjusting the relative weight of information, due to its more segmented structure and rights management: For instance, interviewee B adjusted "Flood Lower Saxony - Offer/Search" in such a way that messages were only published if a moderator approved it, thus preventing inappropriate and irrelevant information. Furthermore, successfully processed requests were deleted afterwards.

Page teams typically not only performed the role of the amplifier but also that of the reporter, acting as a news channel that integrated external resources such as traditional media articles, water level services, and links to further specific or regional communities. Indeed on-site helpers, members of moderator teams (see 
Section 5.1) and affected citizens acted as eyewitnesses to this role, confirming the observation that citizens adopt multiple roles simultaneously (Reuter et al. 2013).

\subsection{Cooperation with Official Emergency Management}

In relation to official emergency management, regional differences regarding the depth of cooperation with volunteers could be observed. While interviewee A was only in touch with the fire service and THW during food distribution, B maintained contact with local emergency service organizations via telephone, so that they could "ask incident control how many people they still needed" (B, 20:56). However, it was not usually possible to establish communication with the emergency services via FB (B, 38:45). Equally, in Passau communication was realized not through $\mathrm{FB}$, but through direct contact to officials:

'Indeed, within one and a half weeks we had been invited to the 'round table', to the big crisis meeting which everyone important was attending. That's where it was all coordinated, who should work together with whom" (C, 22:20).

As the administration of "Moms help" did not constitute an official emergency management organization, they joined the charitable organization "Caritas" to give their work a status (C, 22:20). The initiative "Passau cleans up" ensured contact with official emergency forces in their internal organization in a rather different way:

"Scouts walked through the streets talking to the official forces, asking how many volunteers they needed, and then passed the information 'We need 50 people with shovels and boots' on by word of mouth to the coordinators. They called us (the headquarters), where one member managed a spreadsheet in front of the office, equipped the volunteers and sent them to the coordinators. The scouts picked the volunteers up from there and took them along” (F, 37:20).

This respondent, though acknowledging that she did not know how to support this process using social media, strongly supported the idea that state institutions like the municipality, fire services or THW should be educated in dealing with social media. The author of "Info Page Flood Bavaria 2013" pointed out that although he gathered information from blogs and established media, he relied above all on messages from users, because such messages provided information up to $2 \mathrm{~h}$ in advance of other sources. According to interviewee D, some coordination difficulties resulted through reliance on official information, whereby too many volunteers sometimes went to the contact points mentioned, while there 
were too few helpers at other places (D, 02:34). Because of this suboptimal volunteer coordination, up-to-date information about required number of helpers was published on FB, which meant that indecisive helpers no longer went to these locations. In this case the incident commander could not comprehend why fewer people were arriving, because he was not aware of the current situation on FB (E, 14:14). Such circumstances indicate that the emergency services' exploitation of social media information would improve the optimal allocation of both information and (material) resources.

\section{Results III: Discussion of Challenges and Patterns}

Our examination of social media use revealed some recurring patterns, extending those detected in our preliminary study (Kaufhold and Reuter 2014; Reuter et al. 2015b). Table 4 summarizes the identified challenges regarding the use of ICT

Table 4: Identified Challenges and Actions.

\begin{tabular}{|c|c|c|}
\hline$\#$ & $\begin{array}{l}\text { Challenge identified in } \\
\text { our study }\end{array}$ & Actions and Implications \\
\hline 1 & $\begin{array}{l}\text { Clarity and } \\
\text { representation of } \\
\text { relevant content }\end{array}$ & $\begin{array}{l}\text { - Display the community's goals or purpose } \\
\text { - Display conventions of interaction } \\
\text { - Apply a structure and channeling of information }\end{array}$ \\
\hline 2 & $\begin{array}{l}\text { Feedback and updates in } \\
\text { interaction relationships }\end{array}$ & $\begin{array}{l}\text { - Ensure the timely arrival of information } \\
\text { - Update outdated information }\end{array}$ \\
\hline 3 & $\begin{array}{l}\text { Organizational } \\
\text { identification and } \\
\text { resilience }\end{array}$ & $\begin{array}{l}\text { - Use of photos for emotional processing, solidarity and motivation } \\
\text { - "Exploit" style of message writing to maximize acceptance } \\
\text { - Design proper collaboration between involved stakeholders }\end{array}$ \\
\hline 4 & $\begin{array}{l}\text { Integration of } \\
\text { technologies and } \\
\text { interaction types }\end{array}$ & $\begin{array}{l}\text { - Model organizational embedment of ICT } \\
\text { - Support different tasks with suitable ICT } \\
\text { - Consider public and private ways of interaction }\end{array}$ \\
\hline 5 & $\begin{array}{l}\text { Moderation and } \\
\text { autonomous work }\end{array}$ & $\begin{array}{l}\text { - Use ICT to relieve moderating tasks } \\
\text { - Foster self-regulation of participants } \\
\text { - Consideration of different levels of skills regarding ICT }\end{array}$ \\
\hline 6 & $\begin{array}{l}\text { Maintain quality of } \\
\text { information }\end{array}$ & $\begin{array}{l}\text { - Amplification of relevant information } \\
\text { - Provision of current information } \\
\text { - Provision of geo-visualized information } \\
\text { - Provision of “appealing” information }\end{array}$ \\
\hline
\end{tabular}


and, in particular, social media during the European floods of 2013, and identifies the most common actions intended to overcome these challenges that were undertaken. However, while some challenges could be addressed to a fairly satisfactory degree, most have a considerable room for improvement.

These challenges will be described in the following.

\subsection{Clarity and Representation of Relevant Content}

The description of the FB-group, a fixed posting, and/or the page's info section were used to display the overall goals of the community and to provide conventions on how to behave or use existing infrastructure. This seems to be a crucial aspect for optimizing the process of communication. There also seems to be a fundamental requirement to structure information flow, e.g. use of the file function to create specific documents dealing with certain topics. The annotations within the document titles furthermore indicate the need to display a status representing developments on this topic. These efforts seem to aim towards making relevant help requests more available and listenable (Hughes et al. 2014) to the users, to maintain a clear overview within the interaction platform and to support the interaction between roles, such as moderators, helpers and people in need.

\subsection{Feedback and Updates in Interaction Relationships}

According to our interviewees, a considerable amount of communication took place via private messages for the purposes of privacy as well. Birkbak (2012) already reported on the benefits of an architecture like FB including both public and private spaces. However, there is a high risk that timely feedback will not be received since messages received from people not in one's friend list are filtered into the folder "other." One major challenge is therefore to ensure the timely arrival of information. Moreover, our study showed that cross-platform collaboration requires proper information-update procedures to counter information inconsistencies and redundant resource allocation.

\subsection{Organizational Identification and Resilience}

To motivate affected citizens and volunteers, to generate identification with the helper's efforts and to provide emotional support, it was common practice to upload photos showing the impact of the flood and related relief activities to 
counter it. As a consequence, comments usually contained emotional messages expressing solidarity, sympathy and identification with the helpers, showing the potential of social media to influence a community's resilience in a positive way. Furthermore, the style of message writing seems fundamental to gain a broad acceptance among different cultural or social groups. However, the challenge on how to ensure proper collaboration among authorities, professional response and volunteer communities has to be examined in a more comprehensive and profound manner.

\subsection{Integration of Technologies and Interaction Types}

Regarding the organizational integration of social media, different degrees of relevance were observed. While "Passau cleans up" used social media for the most part to supplement the spread of information and gather some basic information, their central resource was the local organization with headquarters, coordinators and scouts. "Flood Lower Saxony - Offer/Search" used FB as their core platform for coordinating relief activities and information flow. In all cases, Twitter was primarily used to distribute information but not to coordinate. Also, certain degrees of privacy were implemented ranging from "Flood Magdeburg - Requests for help," whereby people were encouraged to publicly exchange their address and contact data, to "Flood Lower Saxony - Offer/Search," whereby sensitive data was instead exchanged by private message and managed with the support of external tools which were only visible to the creator or to a limited audience of invited people. In relation to tools, different degrees of technological integration were studied. In order to master a multitude of different tasks, "Passau cleans up" used blogs, Google docs and external web tools, "Flood News Magdeburg” integrated a Google map into their efforts and "Flood Lower Saxony" disseminated tweets alongside their core FB activities. Tools such as Google Maps and OpenStreetMap could also tighten the connection between real and virtual volunteer activities (Reuter et al. 2013) and support disaster response through voluntary community mapping (Soden and Palen 2014).

\subsection{Moderation and Autonomous Work}

Moderators progressed from simple activities to more complex ones (Starbird and Palen 2011). It also became apparent that the moderation of a community entails considerable overhead and is a very time-consuming process; ICT could reduce the quantity of moderation activities by fostering the self-regulation of 
participants. However, the interviews indicated that there were problems adapting to new technology in emergency situations, which prevented a richer integration of technology in some communities.

\subsection{Maintain Quality of Information}

From the perspective of information quality, several information processing activities as well as supporting functions and tools were identified. Consistent with previously conducted studies (Vieweg et al. 2010; Starbird 2013), we found that page teams and moderators sought to identify, select and amplify relevant information, and provided structured and synthesized posts of information. While geo-visualized information was a perceived aspect of improving the quality of information (Ludwig et al. 2015a), the immediacy of information was seen as a central benefit of social media in supporting the overall coordination of relief activities. In addition, the style of message writing was also seen as an aspect of quality, insofar as it influenced acceptance among of the various citizens and volunteers. For instance, emotionally supportive photos in conjunction with messages written in an appropriate style seem important to promote a positive climate among participants.

\section{Summary and Conclusion}

This contribution examined the actions of virtual communities in disasters by analyzing the contents of social media posts and conducting semi-structured interviews with FB-group and page founders, focusing on the use of social media and ICT in disasters with regards to organizational and information-specific characteristics. The case study of the 2013 European flood bolsters evidence for the relevance of social media during disasters for the citizens of Germany, but also shows perceived deficiencies of current emergency management practices in relation to the use of social media.

In order to answer our first research question "How were different types of social media used during the European floods?" (Section 4), we found that Twitter was used as a platform for status updates, the information space of which was largely constructed through automatic retweet services. While FB-pages were mostly intended to provide an overview and to filter the vast information supply, FB-groups also coordinated a multitude of virtual and real relief activities. This confirms the findings of Hughes et al. (2014). Other tools, 
such as Google Maps, Live Blog and Google Docs and custom web tools have also been used for specific purposes often related to Facebook and Twitter. However, among the examined communities the overall importance of social media varied and different levels of privacy and technological integration were applied.

To approach our second research question "How was social media used to organize volunteers?” (Section 5), we conclude that in addition to affected citizens and (digital) volunteers, some particularly dedicated volunteers adopted the role of moderator to mediate the supply and demand of help through social media and other ICT. Moderators exploited the given functionality of social media and tools they were familiar with to structure the processes of exchanging information, promoting cohesion and organizing volunteers. In contrast, considering organizational barriers of using social media (Reuter et al. 2016) the cooperation with official emergency management rather relied on local communication, meetings and telephone.

To address the third research question "What are the challenges for collaboration support?” (Section 6) we outlined six challenges including (\#1) clarity and representation of relevant content, (\#2) feedback and updates in interaction relationships, (\#3) organizational identification and resilience, (\#4) integration of technologies and interaction types, (\#5) moderation and autonomous work, and (\#6) maintaining quality of information.

Compared to related work, our approach provides several contributions: (A) While there are many studies about social media and digital volunteers in the US (as mentioned in Section 2), fewer studies investigated events in Europe. The point here is that comparative work which might draw out geographical organizational and mobilization differences ought to be valuable. (B) Looking at the 2013 European floods case, existing work focuses "only" on Twitter (Fuchs et al. 2013; Reuter and Schröter 2015), focuses on one particular city (Mildner 2013; Wittmann et al. 2015) or is rather design oriented (Sackmann et al. 2014; Backfried et al. 2015; Reuter et al. 2015b), and does not describe the overall case. In contrast, our study covered different media "beyond Twitter," examining the event in three locations across Germany and made use of both social media and interview data. (C) We also particularly focused on the moderator as an important role in social media emergency response, something that we think has been a little underplayed.

Acknowledgments: The research project "EmerGent" was funded by a grant of the European Union (FP7 No. 608352). We would like to thank all participants of our empirical study. This article builds on a shorter, preliminary analysis (Kaufhold and Reuter 2014). 


\section{References}

Backfried, G., C. Schmidt and G. Quirchmayr (2015) “Cross-Media Linking in Times of Disaster.” In: Proceedings of the Information Systems for Crisis Response and Management (ISCRAM). Kristiansand, Norway.

Birkbak, A. (2012) "Crystallizations in the Blizzard: Contrasting Informal Emergency Collaboration In Facebook Groups." In: Proceedings of the Nordic Conference on HumanComputer Interaction (NordiCHI). Copenhagen, Denmark: ACM-Press, pp. 428-437.

BITKOM. (2013) Soziale Netzwerke 2013 - Eine repräsentative Untersuchung zur Nutzung sozialer Netzwerke im Internet. Berlin: BITKOM.

Creswell, J. W. (2013) Research Design: Qualitative, Quantitative, and Mixed Methods Approaches. New York: Sage Publications.

Fuchs, G., N. Andrienko, G. Andrienko, S. Bothe and H. Stange (2013) "Tracing the German Centennial Flood in the Stream of Tweets: First Lessons Learned." In: SIGSPATIAL International Workshop on Crowdsourced and Volunteered Geographic Information. Orlando, USA, pp. 2-10.

Heverin, T. and L. Zach (2010) "Microblogging for Crisis Communication: Examination of Twitter Use in Response to a 2009 Violent Crisis in the Seattle-Tacoma, Washington Area." In: Proceedings of the Information Systems for Crisis Response and Management (ISCRAM). Seattle, USA.

Hollan, J., E. Hutchins and D. Kirsh (2000) "Distributed cognition: Toward a New Foundation for Human-Computer Interaction Research," ACM Transactions on Computer-Human Interaction, 7(2):174-196.

Hughes, A. L. and L. Palen (2009) "Twitter Adoption and Use in Mass Convergence and Emergency Events." In: (J. Landgren and S. Jul, eds.) Proceedings of the Information Systems for Crisis Response and Management (ISCRAM). Gothenburg, Sweden: ISCRAM.

Hughes, A. L. and L. Palen (2012) "The Evolving Role of the Public Information Officer: An Examination of Social Media in Emergency Management," Journal of Homeland Security and Emergency Management, 9(1). doi:10.1515/1547-7355.1976.

Hughes, A. L. and A. H. Tapia (2015) "Social Media in Crisis: When Professional Responders Meet Digital Volunteers," Journal of Homeland Security and Emergency Management, 12(3):679-706.

Hughes, A. L., L. A. S. Denis, L. Palen and K. M. Anderson (2014) "Online Public Communications by Police \& Fire Services during the 2012 Hurricane Sandy.” In: Proceedings of the Conference on Human Factors in Computing Systems (CHI). Toronto, Canada: ACM-Press, pp. 1505-1514.

Karsten, A. (2013) “Interoperabilität und Agilität: Sachstand und Herausforderung.” In: Interorganisationale Zusammenarbeit im Krisenmanagement. Siegen, Germany: University of Siegen.

Kaufhold, M.-A. and C. Reuter (2014) "Vernetzte Selbsthilfe in Sozialen Medien am Beispiel des Hochwassers 2013/Linked Self-Help in Social Media using the example of the Floods 2013 in Germany," i-com, 13(1):20-28.

Liu, S., L. Palen and J. Sutton (2008) "In Search of the Bigger Picture: The Emergent Role of On-Line Photo Sharing in Times of Disaster." In: Proceedings of the Information Systems for Crisis Response and Management (ISCRAM). Washington, DC, USA.

Ludwig, T., C. Reuter and V. Pipek (2015a) "Social Haystack: Dynamic Quality Assessment of Citizen-Generated Content in Social Media during Emergencies," Transactions on 
Human Computer Interaction (ToCHI), 21(4). Retrieved from http://dl.acm.org/citation. cfm?id=2798442.2749461.

Ludwig, T., C. Reuter, T. Siebigteroth and V. Pipek (2015b) "CrowdMonitor: Mobile Crowd Sensing for Assessing Physical and Digital Activities of Citizens during Emergencies." In: Proceedings of the Conference on Human Factors in Computing Systems (CHI). Seoul, Korea: ACM Press.

Meier, P. (2012) "Crisis Mapping in Action: How Open Source Software and Global Volunteer Networks Are Changing the World, One Map at a Time," Journal of Map \& Geography Libraries, 8(2):89-100.

Mildner, S. (2013) "Bürgerbeteiligung beim Hochwasserkampf - Chancen und Risiken einer kollaborativen Internetplattform zur Koordination der Gefahrenabwehr.” In: (T. Köhler and N. Kahnwald, eds.) Online Communities: Enterprise Networks, Open Education and Global Communication: 16. Workshop GeNeMe '13 Gemeinschaften in Neuen Medien. Dresden, Germany: TUDpress, pp. 13-21.

Palen, L. and S. B. Liu (2007) "Citizen Communications in Crisis: Anticipating a Future of ICT-Supported Public Participation." In: Proceedings of the Conference on Human Factors in Computing Systems (CHI). San Jose, USA: ACM Press.

Perng, S.-Y., M. Büscher, L. Wood, R. Halvorsrud, M. Stiso, L. Ramirez and A. Al-Akkad (2012) "Peripheral Response: Microblogging during the 22/7/2011 Norway Attacks." In: (L. Rothkrantz, J. Ristvej and Z. Franco, eds.) Proceedings of the Information Systems for Crisis Response and Management (ISCRAM). Vancouver, Canada: ISCRAM, pp. 1-11.

Qu, Y., P. F. Wu and X. Wang (2009) “Online Community Response to Major Disaster: A Study of Tianya Forum in the 2008 Sichuan Earthquake." In: Proceedings of the Hawaii International Conference on System Sciences (HICSS). Waikoloa, USA.

Qu, Y., C. Huang, P. Zhang and J. Zhang (2011) "Microblogging after a Major Disaster in China: A Case Study of the 2010 Yushu Earthquake." In: Proceedings of the Conference on Computer Supported Cooperative Work (CSCW). Hangzhou, China: ACM, pp. 25-34.

Reuter, C. and J. Schröter (2015) “Microblogging during the European Floods 2013: What Twitter May Contribute in German Emergencies," International Journal of Information Systems for Crisis Response and Management (IJISCRAM), 7(1):22-41.

Reuter, C., A. Marx and V. Pipek (2012) "Crisis Management 2.0: Towards a Systematization of Social Software Use in Crisis Situations," International Journal of Information Systems for Crisis Response and Management (IJISCRAM), 4(1):1-16.

Reuter, C., O. Heger and V. Pipek (2013) “Combining Real and Virtual Volunteers through Social Media.” In: (T. Comes, F. Fiedrich, S. Fortier, J.Geldermann and T. Müller, eds.) Proceedings of the Information Systems for Crisis Response and Management (ISCRAM). Baden-Baden, Germany: ISCRAM, pp. 1-10.

Reuter, C., T. Ludwig, T. Friberg, S. Pratzler-Wanczura and A. Gizikis (2015a) “Social Media and Emergency Services? Interview Study on Current and Potential Use in 7 European Countries," International Journal of Information Systems for Crisis Response and Management (IJISCRAM), 7(2):36-58.

Reuter, C., T. Ludwig, M. -A. Kaufhold and V. Pipek (2015b) "XHELP: Design of a Cross-Platform Social-Media Application to Support Volunteer Moderators in Disasters." In: Proceedings of the Conference on Human Factors in Computing Systems (CHI). Seoul, Korea: ACM Press.

Reuter, C., T. Ludwig, M. -A. Kaufhold and T. Spielhofer (2016) "Emergency Services Attitudes towards Social Media: A Quantitative and Qualitative Survey across Europe," International Journal on Human-Computer Studies (IJHCS), in press.

Rizza, C., Â. G. Pereira and P. Curvelo (2014) ““"Do-it-Yourself Justice”: Considerations of Social Media use in a Crisis Situation: The Case of the 2011 Vancouver Riots," International 
Journal of Information Systems for Crisis Response and Management (IJISCRAM), 6(4):42-59.

Sackmann, S., M. Hofmann and H. J. Betke (2014) "Organizing On-Site Volunteers: An App-Based Approach." In: Proceedings of the 2014 Ninth International Conference on Availability, Reliability and Security. Washington, DC, USA: IEEE Computer Society, pp. 438-439.

Soden, R. and L. Palen (2014) "From Crowdsourced Mapping to Community Mapping: The Post-Earthquake Work of OpenStreetMap Haiti." In: COOP 2014 - Proceedings of the 11th International Conference on the Design of Cooperative Systems, 27-30 May 2014, Nice (France). pp. 311-326. doi:10.1007/978-3-319-06498-7.

St. Denis, L. A., K. M. Anderson and L. Palen (2014) "Mastering Social Media: An Analysis of Jefferson County's Communications during the 2013 Colorado Floods." In: 11th International ISCRAM Conference. pp. 737-746.

Stake, R. E. (1995) The Art of Case Study Research. New York: Sage Publications.

Stallings, R. A. and E. L. Quarantelli (1985) “Emergent Citizen Groups and Emergency Management," Public Administration Review, 45(Special Issue):93-100.

Starbird, K. (2013) "Delivering Patients to Sacré Coeur: Collective Intelligence in Digital Volunteer Communities." In: Proceedings of the Conference on Human Factors in Computing Systems (CHI). Paris, France: ACM-Press, pp. 801-810.

Starbird, K. and L. Palen (2010) "Pass It On?: Retweeting in Mass Emergency.” In: Proceedings of the Information Systems for Crisis Response and Management (ISCRAM). Seattle, USA, pp. 1-10.

Starbird, K. and L. Palen (2011) "Voluntweeters: Self-Organizing by Digital Volunteers in Times of Crisis." In: Proceedings of the Conference on Human Factors in Computing Systems $(\mathrm{CHI})$. Vancouver, Canada: ACM-Press.

Starbird, K. and L. Palen (2012) "(How) Will the Revolution be Retweeted? Information Diffusion and the 2011 Egyptian Uprising." In: Proceedings of the Conference on Computer Supported Cooperative Work (CSCW). Seattle, USA: ACM-Press, pp. 7-16.

Strauss, A. L. and J. Corbin (1998) Basics of Qualitative Research: Techniques and Procedures for Developing Grounded Theory. New York: Sage Publications.

Sutton, J. (2010) "Twittering Tennessee: Distributed networks and Collaboration Following a Technological Disaster.” In: (S. French, B. Tomaszewski and C. Zobel, eds.) Proceedings of the Information Systems for Crisis Response and Management (ISCRAM). Seattle, USA: ISCRAM.

Vieweg, S., A. L. Hughes, K. Starbird and L. Palen (2010) “Microblogging During Two Natural Hazards Events: What Twitter May Contribute to Situational Awareness." In: Proceedings of the Conference on Human Factors in Computing Systems (CHI). Atlanta, USA: ACM-Press, pp. 1079-1088.

White, J. I., L. Palen and K. M. Anderson (2014) "Digital Mobilization in Disaster Response: The Work \& Self - Organization of On-Line Pet Advocates in Response to Hurricane Sandy." In: Proceedings of the Conference on Computer Supported Cooperative Work (CSCW). Baltimore, USA: ACM.

Wittmann, S., M. Jurisch and H. Krcmar (2015) "Managing Network Based Governance Structures in Disasters: The Case of the Passau Flood in 2013," Journal of Homeland Security and Emergency Management, 12(3):529-569.

Yin, R. K. (2014) Case Study Research: Design and Methods. New York: SAGE Pub. 